\title{
Cluster-Inspired Design of High-Capacity Anode for Li-Ion Batteries
}

$$
\text { Tianshan Zhao, }{ }^{\dagger} \ddagger \text { Qian Wang, }{ }^{*}, \uparrow \text { and Puru Jena }{ }^{*}, *
$$

${ }^{\dagger}$ Center for Applied Physics and Technology, College of Engineering, Peking University, Key Laboratory of High Energy Density Physics Simulation, and IFSA Collaborative Innovation Center, Ministry of Education, Beijing 100871, China

${ }^{ \pm}$Department of Physics, Virginia Commonwealth University, Richmond, Virgina 23284, Untied States

*E-mail: qwang2@pku.edu.cn

*E-mail: pjena@vcu.edu

\section{Stability relative to other $\mathrm{Ti}-\mathrm{C}$ compounds}

We compare the calculated cohesive energy of $1 \mathrm{D} \mathrm{Ti}_{9} \mathrm{C}_{13}$ nanowire with those of 1D $\mathrm{Ti}_{8} \mathrm{C}_{12}$ nanowire, $\mathrm{Ti}_{13} \mathrm{C}_{22}$ and $\mathrm{Ti}_{8} \mathrm{C}_{12}$ isolated clusters, bulk TiC, 1D TiC nanowire, and some other Ti-C binary compounds. The relative stability of a compound with the composition $\mathrm{Ti}_{x} \mathrm{C}_{1-x}$ was calculated using the method described by Zhang et al. ${ }^{1}$. We define the molar formation energy $\delta F$ as,

$$
\delta F\left(T i_{x} C_{1-x}\right)=E_{c o h}\left(T i_{x} C_{1-x}\right)-x \mu_{T i}-(1-x) \mu_{C}
$$

where $E_{c o h}(x)$ is the cohesive energy of the system, and $\mu_{T i}$ and $\mu_{C}$ are the chemical potentials of the $\mathrm{Ti}$ and $\mathrm{C}$ atoms, respectively. The relative stability of 
different $\mathrm{Ti}_{x} \mathrm{C}_{1-x}$ structures can be gauged by comparing their $\delta F$ : higher $\delta F$ means lower stability. We set $\mu_{C}$ and $\mu_{T i}$ as the chemical potential of graphene and bulk hcp Ti. We used the chemical potential of graphene instead of graphite as reference so that our calculated cohesive energy can be directly compared with that of two-dimensional Tetragonal TiC monolayer sheet and nanoribbons considered by the authors of Ref. 1 . The results are summarized in Figure 1b. A line connecting the cohesive energy of graphene and bulk $\mathrm{Ti}$ is used to estimate the relative stability of a Ti-C compound: a composition with cohesive energy below the line $(\delta F<=0)$ is stable against decomposition into graphene and $\mathrm{Ti}$; when $\delta F>0$, the structure becomes metastable or even unstable.

The $\mathrm{Ti}_{13} \mathrm{C}_{22}$ along with other Ti-C clusters observed in experiment ${ }^{2}$ have a positive $\delta F$ and hence are metastable since they are in the gas phase. In contrast, the 1D $\mathrm{Ti}_{9} \mathrm{C}_{13}$ in our work has a negative $\delta F,-0.236 \mathrm{eV}$, indicating its thermodynamic stability. The experimentally identified bulk TiC and MXenes all have negative $\delta F$. One should note that only OD clusters, with positive $\delta F$, have been experimentally synthesized. Compared with the cohesive energy of $1 \mathrm{D}$ TiC nanowire, $1 \mathrm{D} \mathrm{Ti}_{9} \mathrm{C}_{13}$ is only $0.03 \mathrm{eV}$ per atom higher in energy (see Figure $1 \mathrm{~b}$ ) which is one-third of the energy difference, namely, $0.1 \mathrm{eV}$, between diamond and graphite. ${ }^{3}$ Therefore, the 1D $\mathrm{Ti}_{9} \mathrm{C}_{13}$ is thermodynamically favorable and may be formed by layer-growth observed in $\mathrm{Ti}_{13} \mathrm{C}_{22}{ }^{2}$

\section{Dynamic stability}


We first calculate the phonon dispersion and phonon density of states (DOS) to ensure the dynamical stability of the $\mathrm{Ti}_{9} \mathrm{C}_{13}$ structure. The calculated results are potted in Figure $\mathrm{S} 1 \mathrm{a}$ which clearly indicates that the $\mathrm{Ti}_{9} \mathrm{C}_{13}$ is dynamically stable as no imaginary frequencies exist in the entire Brillouin zone. A significant phonon gap is observed in the band dispersion, separating the vibrational modes into low frequency $0-900 \mathrm{~cm}^{-1}$ and high frequency $1750-1800 \mathrm{~cm}^{-1}$ region. The phonon DOS shows that the high frequency modes are entirely contributed by atoms in the $\mathrm{C}_{2}$ dimer and the partial DOS of $\mathrm{C}_{2}$ and total DOS overlap in the high frequency region. It is indicated that the high frequency modes correspond to vibrations of the $\mathrm{C}_{2}$ dimer's double bond. The three acoustic bands are mainly contributed by Ti due to its large atomic mass. In addition, there is a very small gap (about $20 \mathrm{~cm}^{-1}$ ) between the first optical band and acoustic bands at the $\Gamma$ point.

\section{Thermal stability}

To examine the thermal stability of the $\mathrm{Ti}_{9} \mathrm{C}_{13}$ structure, we performed ab initio molecular dynamics (AIMD) simulations with Nóse heat bath scheme at 2500K using a relatively large $(4 \times 1 \times 1)$ supercell because a smaller unit cell may easily result in false instability. The time step is set to 1 femtosecond $(f s)$. After 5 picoseconds $(p s)$ of simulation, no structural distortion or reconstruction is found, and the average total potential energy keeps nearly constant (see Figure $\mathrm{S} 1 \mathrm{~b}$ ), confirming that $\mathrm{Ti}_{9} \mathrm{C}_{13}$ is thermally stable at high temperature. The excellent thermal stability of $\mathrm{Ti}_{9} \mathrm{C}_{13}$ provides the possibility of its future synthesis and application under ambient conditions. 


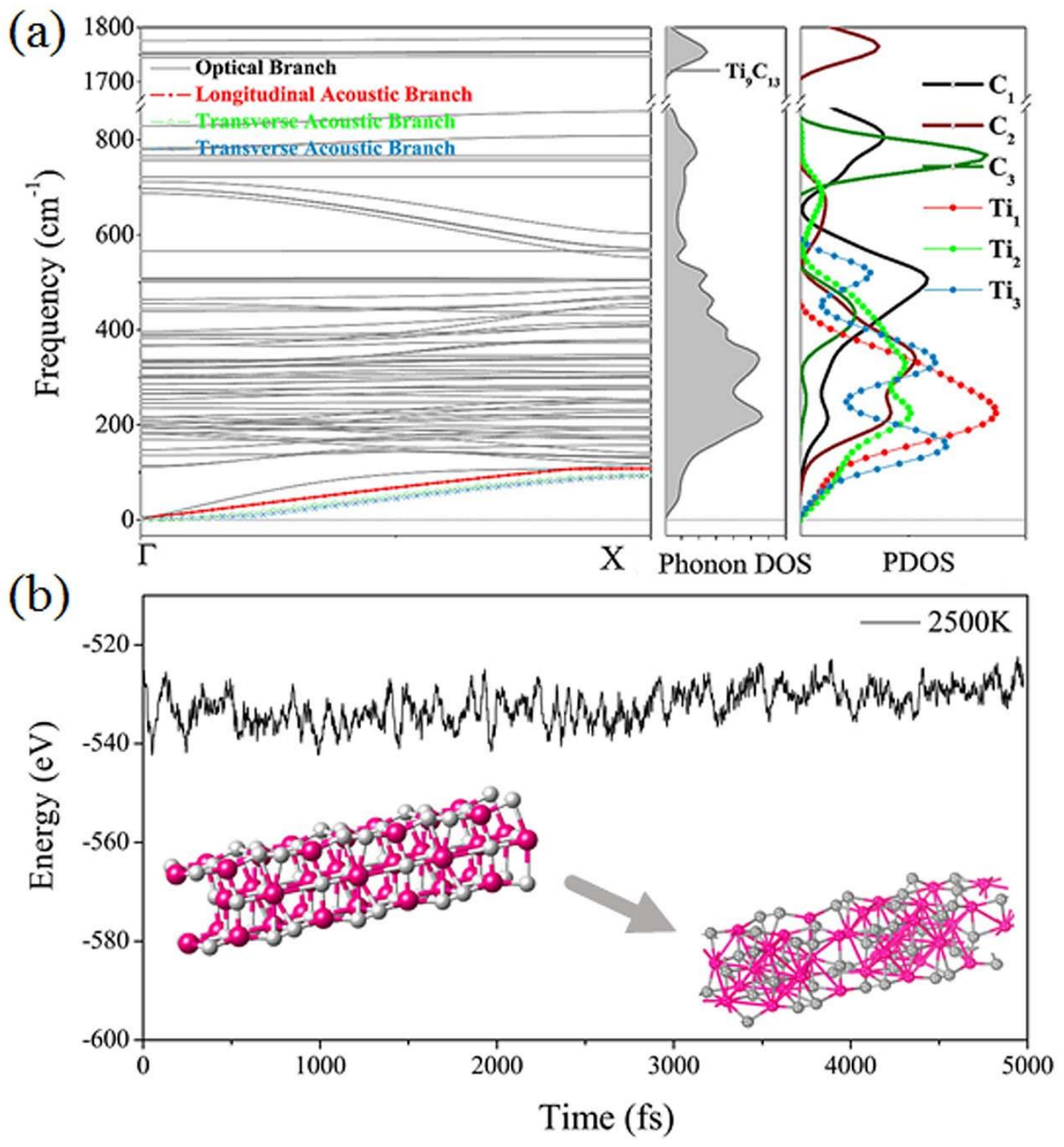

Figure S1. (a) Phonon dispersion and density of states of the $\mathrm{Ti}_{9} \mathrm{C}_{13}$ structure. (b)

Thermodynamic stability of $\mathrm{Ti}_{9} \mathrm{C}_{13}$ studied with $a b$ initio molecular dynamics simulation at $2500 \mathrm{~K}$.

\section{Thermodynamic properties}

Based on the calculated phonon spectrum, a series of thermodynamic properties are derived. Here, we concentrate on studies of the heat capacity and Debye temperature of the $\mathrm{Ti}_{9} \mathrm{C}_{13}$ nanowire. The calculated phonon heat capacity with respect 
to temperature is plotted in Fig. S 2 (a). The heat capacity can also be expressed using the phonon DOS. ${ }^{4}$ The Debye temperature $\Theta_{D}=h v_{D} / k_{B}$ is determined by fitting the calculated $C_{V^{-}} T$ curve using the Debye model. The fitted Debye temperature $\Theta_{D}(T)$ is given in Fig. $\mathbf{S} 2$ (b) which shows that $\Theta_{D}(T)$ is as high as $800 \mathrm{~K}$ at room temperature. Since the vibrational frequency is proportional to the square root of the stiffness within the harmonic approximation, $\Theta_{D}$ can be used as a measure of the "stiffness" of solids. ${ }^{4}$ Therefore, we see from Fig. S 2 (b) that the $\mathrm{Ti}_{9} \mathrm{C}_{13}$ sheet can display large Debye stiffness due to its high Debye temperature, resulting from the covalent $\mathrm{C}=\mathrm{C}$ bonds.

As phonons are subjected to Bose-Einstein distribution, the weighted phonon DOS $g(v) \mathrm{W}\left(h v / k_{B} T\right)$ describes the contribution of vibrational modes with a certain frequency to the heat capacity. The frequency and temperature dependence of the weighted phonon DOS is plotted in Figure S2c. We find that at $50 \mathrm{~K}$, only about $2.5 \%$ or even less weighting factor $\mathrm{W}\left(h v / k_{B} T\right)$ exists in the frequency region over $400 \mathrm{~cm}^{-1}$, indicating that only low-frequency modes contribute to the heat capacity at low temperature. This is evidenced in Figure S2d showing the variation of the weighted phonon DOS with respect to frequency at different temperatures. Since the heat capacity defined by the Debye model is proportional to the cross section of Frequency-Phonon DOS at a given temperature, a larger amount of heat is required to increase the temperature by one Kelvin when the cross-section is larger. Because $\mathrm{Ti}_{9} \mathrm{C}_{13}$ has more vibrational states than graphite and diamond ${ }^{4}$ in the low frequency region, $\mathrm{Ti}_{9} \mathrm{C}_{13}$ exhibits larger heat capacity at $850 \mathrm{~K}$. 

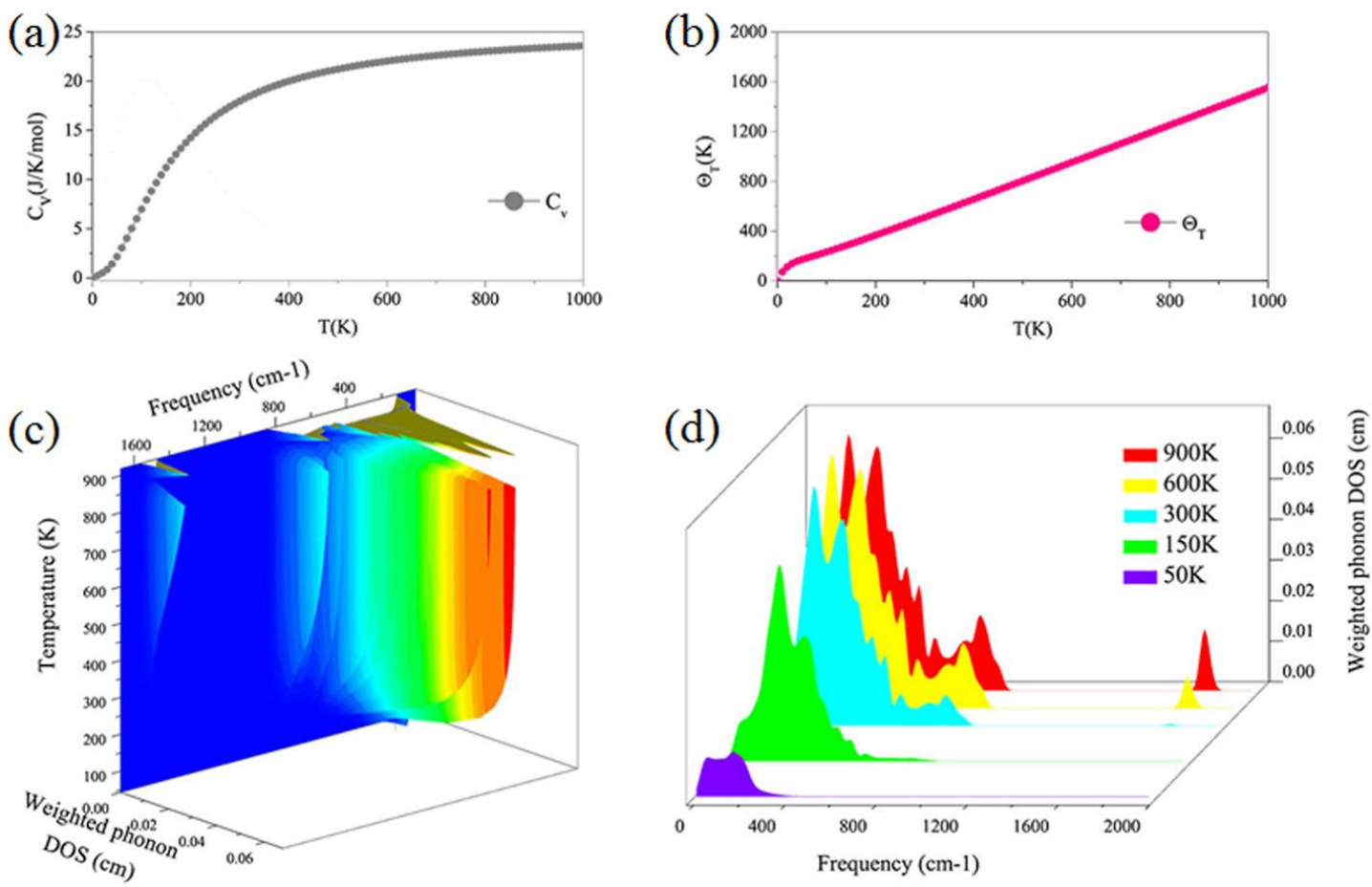

Figure S2. (a) Heat capacity, and (b) Debye temperature of $\mathrm{Ti}_{9} \mathrm{C}_{13}$ as a function of temperature; (c) 3D plot of the weighted phonon DOS (W-P-DOS) as a function of frequency and temperature; (d) Cross sections of the W-P-DOS at 50, 150, 300, 600, and $900 \mathrm{~K}$.

\section{Volume expansion/contraction during lithiation/delithiation process}

We use the variations of lattice constant and bond length (see Table S1) to measure the change of volume during lithiation/delithiation.

The volume $(\mathrm{V})$ of the nanowire is estimated by

$$
V=\frac{\left(2 b_{T i_{1}-C_{1}}+2 b_{T i_{3}-C_{3}}\right)}{2} \times\left[\frac{\left(2 b_{T i_{3}-C_{1}}+2 b_{T_{i_{1}}-C_{3}}\right)}{2}\right]^{2}
$$

where $b_{\mathrm{Ti1}-\mathrm{C} 1}, b_{\mathrm{Ti} 3-\mathrm{C} 3}, b_{\mathrm{Ti} 1-\mathrm{C} 3}$ and $b_{\mathrm{Ti3}-\mathrm{C} 1}$ are the bond lengths between $\mathrm{Ti}_{1}-\mathrm{C}_{1}, \mathrm{Ti}_{3^{-}}$ $\mathrm{C}_{3}, \mathrm{Ti}_{1}-\mathrm{C}_{3}$, and $\mathrm{Ti}_{3}-\mathrm{C}_{1}$ atoms (see Table $\mathrm{S} 1$ ).

We found that the volume expansions are only $0.04 \%$ and $1.3 \%$ for $\mathrm{Ti}_{9} \mathrm{C}_{13} \mathrm{Li}_{20}$ 
and $\mathrm{Ti}_{9} \mathrm{C}_{13} \mathrm{Li}_{56}$ which are negligible. In addition, we also calculated the specific capacity of LIB composed of $1 \mathrm{D}$ TiC nanowire $\left(\mathrm{Ti}_{9} \mathrm{C}_{9}\right)$. 1D $\mathrm{TiC}$ nanowire also shows little volume change $(3.02 \%$ and $1.71 \%)$ during lithiation/delithiation as given in Table S1.

Table S1. Comparison of lattice constant $(\AA)$, different bond lengths ( $\mathrm{A}$ ) of Ti and C atoms and volume $\left(\AA^{3}\right)$ of $\mathrm{Ti}_{9} \mathrm{C}_{13}$ during lithiation/delithiation process.

\begin{tabular}{lccccccc}
\hline \hline Length $(\AA)$ & $\mathrm{Ti}_{9} \mathrm{C}_{13}$ & $\mathrm{Ti}_{9} \mathrm{C}_{13} \mathrm{Li}_{20}$ & $\mathrm{Ti}_{9} \mathrm{C}_{13} \mathrm{Li}_{56}$ & $\mathrm{Ti}_{9} \mathrm{C}_{9}$ & $\mathrm{Ti}_{9} \mathrm{C}_{9} \mathrm{Li}_{16}$ & $\mathrm{Ti}_{9} \mathrm{C}_{9} \mathrm{Li}_{28}$ \\
\hline$l_{\text {Lattice constant }}$ & 5.142 & 5.142 & 5.142 & 4.220 & 4.220 & 4.220 \\
bond $_{\mathrm{Ti1}-\mathrm{C} 1}$ & 2.262 & 2.881 & 2.571 & 2.571 & 2.109 & 2.110 & 2.109 \\
bond $_{\mathrm{Ti1} 1 \mathrm{C} 2}$ & 2.494 & 2.336 & 2.511 & 2.511 & - & - & - \\
bond $_{\mathrm{Ti1} 1 \mathrm{C} 3}$ & 2.030 & 2.054 & 2.062 & 2.108 & 2.076 & 2.090 \\
bond $_{\mathrm{Ti2}-\mathrm{C} 1}$ & 1.989 & 1.997 & 2.005 & - & - & - \\
bond $_{\mathrm{Ti2}-\mathrm{C} 2}$ & 2.022 & 1.995 & 2.003 & - & - & - \\
bond $_{\mathrm{Ti3}-\mathrm{C} 1}$ & 2.108 & 2.085 & 2.103 & - & - & - \\
bond $_{\mathrm{Ti3}-\mathrm{C} 3}$ & 2.307 & 2.835 & 2.571 & 2.571 & - & - & - \\
bond $_{\mathrm{Cdimer}}$ & 1.280 & 1.320 & 1.318 & - & - & - \\
Volume $\left._{\text {(A }}{ }^{3}\right)$ & 88.068 & 88.091 & 89.204 & 75.01 & 72.74 & 73.73 \\
\hline \hline
\end{tabular}

To study if $\mathrm{Li}$ atoms would prefer to occupy the interior sites of the nanowire instead of the surface sites, we have calculated the energies for different configurations. The results are given in Figure S3. The energy of the structure where 
$\mathrm{Li}$ is intercalated inside the $\mathrm{Ti}_{9} \mathrm{C}_{18}$ nanowire is $0.738 \mathrm{eV}, 0.422 \mathrm{eV}$, and $0.645 \mathrm{eV}$ higher than that of the $\mathrm{Li}_{\mathrm{I}}, \mathrm{Li}_{\mathrm{II}}$, and $\mathrm{Li}_{\mathrm{III}}$ configuration in Figure $4 \mathrm{a}$ of the text, making it unlikely that $\mathrm{Li}$ can reside in the interior of the nanowire.

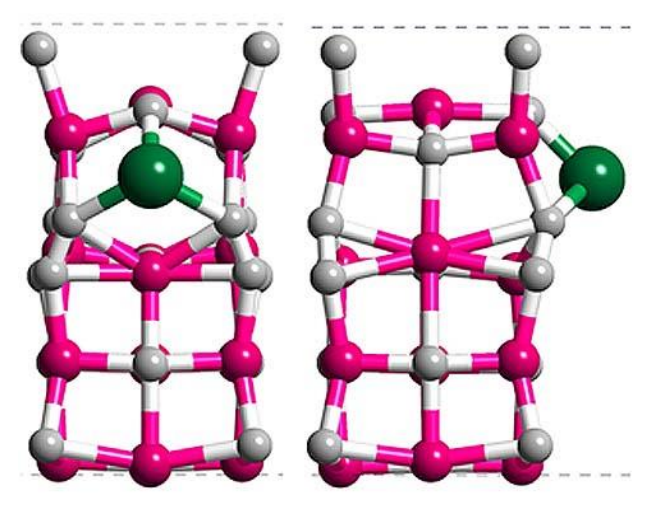

$$
\Delta=0 \mathrm{eV}
$$

$$
\mathrm{Li}_{\text {(outside) }}
$$


$\Delta=0.738 \mathrm{eV}$

$$
\mathrm{Li}_{\text {(inside) }}
$$

Figure S3. Optimized configurations of Li adsorbed outside and intercalated inside the $\mathrm{Ti}_{9} \mathrm{C}_{13}$ nanowire $\left(\mathrm{Ti}_{18} \mathrm{C}_{26} \mathrm{Li}\right)$. The energies are measured with respect to the most stable configuration, i.e. Li on the outside surface.

\section{Open circuit voltage (OCV) and Specific capacity}

Typically, the anode charge/discharge processes assume the following reaction that involves $\mathrm{Li} / \mathrm{Li}^{+}$:

$$
\mathrm{Ti}_{9} \mathrm{C}_{13}+x \mathrm{Li}^{+}+x e^{-} \leftrightarrows \mathrm{Ti}_{9} \mathrm{C}_{13} \mathrm{Li}_{x}
$$

The (OCV) for an intercalation reaction involving $x \mathrm{Li}^{+}$ions is computed from the energy difference of the products and the reactants.

The electronic potential during this process can be written in terms of the Gibbs free energy:

$$
V=-\Delta G_{f} / z F
$$


where $z$ and $F$ are the number of valence electrons during the lithiation process and the Faraday constant, respectively; $\Delta G_{f}$ is the change in Gibbs free energy during the lithiation process and is defined as:

$$
\Delta G_{f}=\Delta E_{f}+P \Delta V_{f}-T \Delta S_{f}
$$

$P \Delta V_{f}$ is of the order of $10^{-5} \mathrm{eV}$ and the term $T \Delta S_{f}$ is about $26 \mathrm{meV}$ at low temperature ${ }^{5-6}$ As standard DFT calculations only predict ground state properties at 0 $\mathrm{K}$, we study the effect of temperature on $\mathrm{Li}$ storage properties of the $\mathrm{Ti}_{9} \mathrm{C}_{13}$ nanowire by calculating the temperature dependence of Gibbs free energy. At dilute concentration, the volume change upon $\mathrm{Li}$ adsorption can be neglected $(p V=0)$, thereby, the Gibbs energy becomes the Helmholtz free energy. We find that the free energy only increases by $0.04 \mathrm{eV} / \mathrm{f}$. u. when the temperature rises from $0 \mathrm{~K}$ to $300 \mathrm{~K}$. Our results indicate that the entropy (thermal) effect is marginal when studying the thermodynamics and kinetics of $\mathrm{Li}$; hence our conclusions drawn from ground state DFT calculations are justified and may be extended to room temperature. Thus, the entropy (thermal) effects and pressure terms are negligible, and will not be discussed further. $\Delta \mathrm{G}_{f}$ is then approximately equal to the formation energy, $\Delta \mathrm{E}_{f}$, involved in the adsorption process, which is defined as:

$$
\Delta E_{f}=E\left(T i_{9} C_{13}\right)+x E(L i)-E\left(T i_{9} C_{13} L i_{x}\right)
$$

Here $E\left(\mathrm{Ti}_{9} \mathrm{C}_{13}\right), E(\mathrm{Li})$, and $E\left(\mathrm{Ti}_{9} \mathrm{C}_{13} \mathrm{Li}_{x}\right)$ represent the free energies (total energy at $0 \mathrm{~K}$ ) of pristine $\mathrm{Ti}_{9} \mathrm{C}_{13}, \mathrm{Li}$ in bcc bulk, and the $\mathrm{Li}$-adsorbed $\mathrm{Ti}_{9} \mathrm{C}_{13}$, respectively. The OCV is related to the formation energy by:

$$
O C V=\Delta G_{f} / x \approx \Delta E_{f} / x \approx\left[E\left(T i_{9} C_{13}\right)+x E(L i)-E\left(T i_{9} C_{13} L i_{x}\right)\right] / \mathrm{e} x
$$


In addition, the specific capacity $(C)$ of LIB is estimated by;

$$
\begin{gathered}
C=\frac{n_{L i} e}{m_{\text {Cell }}}=\frac{n_{L i} \cdot 1.60218 \times 10^{-19} C}{m_{\text {Cell }}}=\frac{n_{L i} \cdot 1.60218 \times 10^{-19} A \cdot s}{M_{\text {Cell }} / N_{A} g} \\
C=\frac{n_{L i} \cdot 1.60218 \times 10^{-19} A \cdot s}{M_{\text {Cell }} / 6.02205 \times 10^{23} g}=\frac{n_{L i} \cdot 1.60218 \times 10^{-19} \cdot \frac{1}{3.6} m A \cdot h}{M_{\text {Cell }} / 6.02205 \times 10^{23} g} \\
C=26801 \frac{n_{L i}}{M_{\text {Cell }}} m A \cdot h / g
\end{gathered}
$$

where $n_{\mathrm{Li}}$ is the adsorbed electric charges (in mol) per mole of electrode materials, $N_{A}$ is the Avogadro number, $e$ is the elementary charge, and $M_{\text {cell }}$ is the molar mass of the anode material. Here, the molar masses of $\mathrm{Ti}_{9} \mathrm{C}_{13} \mathrm{Li}_{56}$ and $\mathrm{Ti}_{9} \mathrm{C}_{9} \mathrm{Li}_{28}$ are 973.14 and 736.02, respectively. Their corresponding specific capacities are $1542 \mathrm{mAh} / \mathrm{g}$ and $1019 \mathrm{mAh} / \mathrm{g}$, respectively.

We calculated the $\mathrm{OCV}$ as a function of $\mathrm{Li}$ concentration $x\left(\mathrm{Ti}_{9} \mathrm{C}_{13} \mathrm{Li}_{x}\right.$, and $\mathrm{Ti}_{9} \mathrm{C}_{9} \mathrm{Li}_{x}$ with $x$ ranging from 1 to 16 . The results are given in the following Figure S4. The OVC decreases from $1.767 \mathrm{~V}$ per atom to $1.241 \mathrm{~V}$ per atom in the $\mathrm{Ti}_{9} \mathrm{C}_{13}$ nanowire as $x$ increases from 1 to 16 . The $\mathrm{OCV}$ of the $\mathrm{Ti}_{9} \mathrm{C}_{9}$ nanowire, namely 1.988 eV, changes little with Li coverage (see Figure S4). 


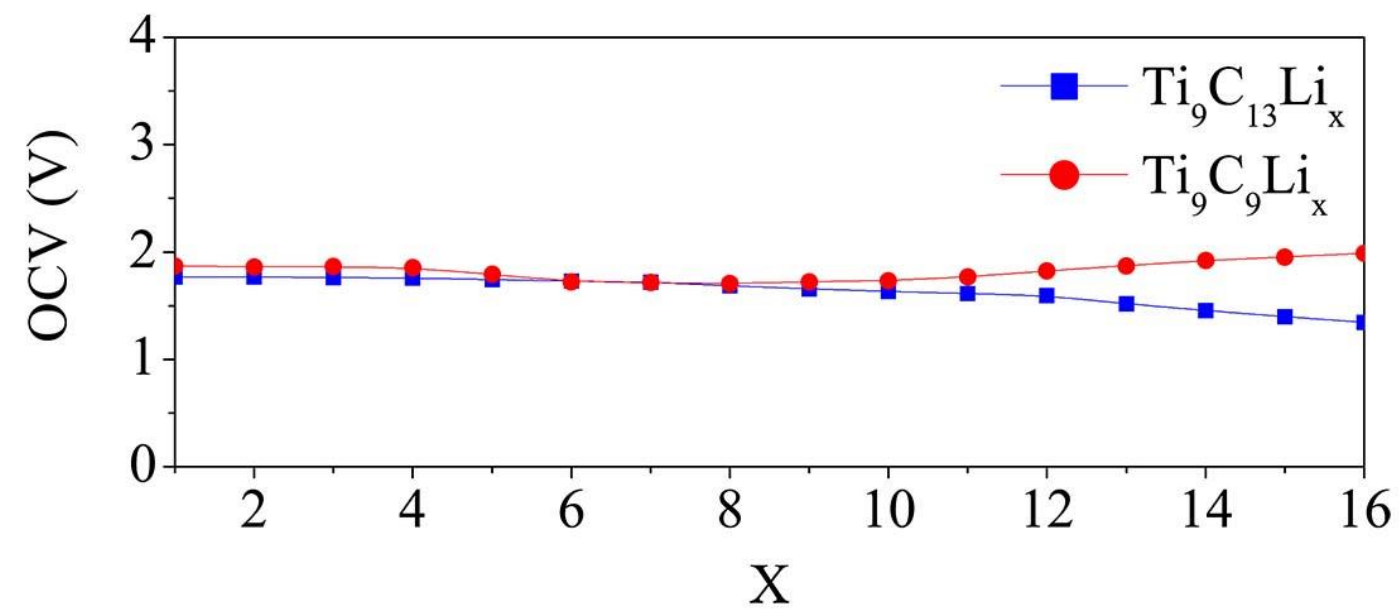

Figure S4. The dependence of OCV on Lithium coverage $x$ in $\mathrm{Ti}_{9} \mathrm{C}_{13} \mathrm{Li} x$, and $\mathrm{Ti}_{9} \mathrm{C}_{9} \mathrm{Li}_{\mathrm{x}}$ nanowires ( $\mathrm{x}$ ranging from 1 to 16). The definition of OCV is given in SI part VI).

(a)
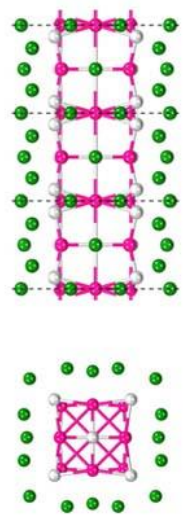

$\mathrm{Ti}_{9} \mathrm{C}_{13} \mathrm{Li}_{20}$

Binding energy $0.980 \mathrm{eV}$ per Li (b)
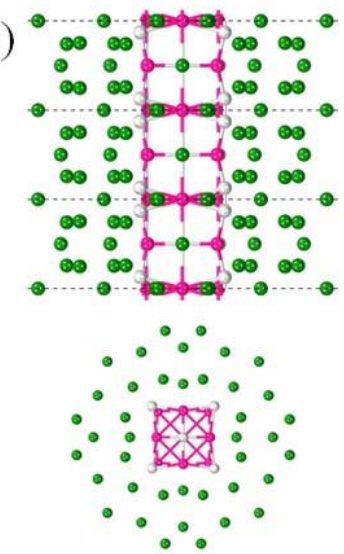

$$
\mathrm{Ti}_{9} \mathrm{C}_{13} \mathrm{Li}_{56}
$$

Binding energy $0.858 \mathrm{eV}$ per $\mathrm{Li}$ (c)
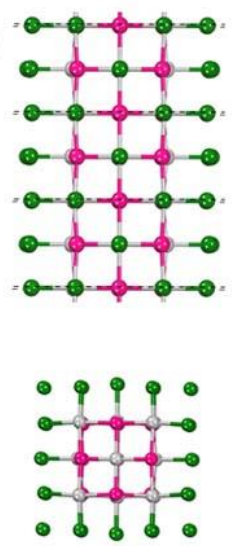

$\mathrm{Ti}_{9} \mathrm{C}_{9} \mathrm{Li}_{16}$

Binding energy $1.988 \mathrm{eV}$ per $\mathrm{Li}$ (d)
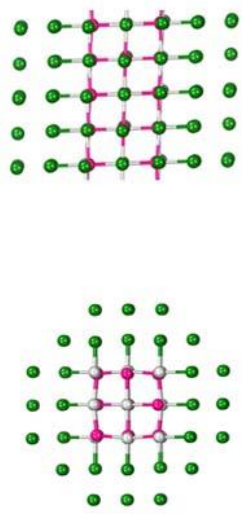

$\mathrm{Ti}_{9} \mathrm{C}_{9} \mathrm{Li}_{28}$

Binding energy $1.132 \mathrm{eV}$ per $\mathrm{Li}$

Figure S5. Optimized structures of (a) lithiated $\mathrm{Ti}_{9} \mathrm{C}_{13} \mathrm{Li}_{20}$, (b) $\mathrm{Ti}_{9} \mathrm{C}_{13} \mathrm{Li}_{56}$, (c) $\mathrm{Ti}_{9} \mathrm{C}_{9} \mathrm{Li}_{16}$, and (d) $\mathrm{Ti}_{9} \mathrm{C}_{9} \mathrm{Li}_{28}$.

\section{REFERENCES}

(1) Zhang, Z.; Liu, X.; Yakobson, B. I.; Guo, W. Two-Dimensional Tetragonal TiC 
Monolayer Sheet and Nanoribbons. J. Am. Chem. Soc. 2012, 134, 19326-19329.

(2) Wang, L.-S.; Cheng, H. Growth Pathways of Metallocarbohedrenes: Cagelike or Cubic? Phys. Rev. Lett. 1997, 78, 2983-2986.

(3) Zhang, S.; Wang, Q.; Chen, X.; Jena, P. Stable Three-dimensional Metallic Carbon with Interlocking Hexagons. Proc. Natl. Acad. Sci. 2013, 110, 18809-18813.

(4) Tohei, T.; Kuwabara, A.; Oba, F.; Tanaka, I. Debye Temperature and Stiffness of Carbon and Boron Nitride Polymorphs from First Principles Calculations. Phys. Rev. B 2006, 73, 064304.

(5) Aydinol, M. K.; Kohan, A. F.; Ceder, G.; Cho, K.; Joannopoulos, J. Ab initio Study of Lithium Intercalation in Metal Oxides and Metal Dichalcogenides. Phys. Rev. B 1997, 56, 1354-1365.

(6) Van der Ven, A.; Aydinol, M. K.; Ceder, G.; Kresse, G.; Hafner, J. First-principles Investigation of Phase Stability in $\mathrm{Li}_{\mathrm{x}} \mathrm{CoO}_{2}$. Phys. Rev. B 1998, 58, 2975-2987. 